\title{
Effects of oral calcium bolus supplementation on intracellular polymorphonuclear leukocyte calcium levels and functionality in primiparous and multiparous dairy cows
}

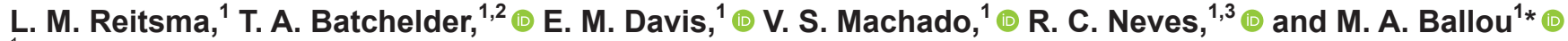 \\ ${ }^{1}$ Department of Veterinary Sciences, Texas Tech University, Lubbock 79409 \\ ${ }^{2}$ Veterinary Medicine Teaching and Research Center, University of California Davis, Tulare 93274 \\ ${ }^{3}$ Department of Veterinary Clinical Sciences, Purdue University, West Lafayette, IN 47907
}

\begin{abstract}
The objectives of this study were (1) to characterize Ca levels and polymorphonuclear leukocyte (PMN) function in primiparous and multiparous animals following oral $\mathrm{Ca}$ bolus supplementation, and (2) to determine differential responses of boluses containing a lower dose of Ca than traditionally used in primiparous animals on Ca levels and PMN function. Jersey $\times$ Holstein crossbred animals $(\mathrm{n}=104)$ were enrolled within $24 \mathrm{~h}$ of parturition. All animals were blocked by time relative to calving and randomly assigned to treatment. The Ca boluses were composed of a mixture of Ca chloride, Ca sulfate, and Ca propionate. For objective 1 , animals were assigned to control (CON; no Ca supplementation), or a series of $2 \mathrm{Ca}$ boluses given $24 \mathrm{~h}$ apart for a total of $50 \mathrm{~g}$ of Ca. Objective 2 treatments included control (CON; no Ca supplementation), a series of $2 \mathrm{Ca}$ boluses given $24 \mathrm{~h}$ apart containing 50 $\mathrm{g}$ of $\mathrm{Ca}$, or a series of $2 \mathrm{Ca}$ boluses given $24 \mathrm{~h}$ apart containing $25 \mathrm{~g}$ of Ca. Blood samples were collected on d $1(<24 \mathrm{~h}), 2,3,5$, and 7 relative to parturition. Total serum Ca, serum haptoglobin, PMN intracellular $\mathrm{Ca}$, PMN intracellular Ca after stimulation with an environmental Escherichia coli, PMN L-selectin surface expression, and PMN phagocytic and oxidative burst activities were analyzed. For objective 1 a tendency was detected for a treatment difference on basal intracellular PMN Ca and a treatment difference on $E$. coli-stimulated intracellular PMN Ca. We detected a parity $\times$ DIM effect for PMN oxidative burst intensity. However, no other interactions or parity effects on other functional PMN variables were detectable. In primiparous animals, we found a treatment difference for E. coli-stimulated intracellular PMN Ca among ani-
\end{abstract}

Received May 4, 2020.

Accepted July 30, 2020.

*Corresponding author: michael.ballou@ttu.edu mals given $50 \mathrm{~g}$ of $\mathrm{Ca}$ but no treatment difference on basal intracellular PMN Ca. The $50 \mathrm{~g}$ of Ca treatment increased both PMN phagocytosis and oxidative burst intensities. Supplementing animals with $50 \mathrm{~g}$ of oral Ca increased intracellular PMN Ca and influenced PMN function.

Key words: calcium, hypocalcemia, polymorphonuclear leukocyte

\section{INTRODUCTION}

The transition period is a critical time for a dairy cow. Diseases encountered during this time have the potential to negatively influence health and production in the subsequent lactation. Approximately $75 \%$ of disease occurs in the first month after calving (LeBlanc et al., 2006). Two weeks before calving, peripheral blood mononuclear cell function decreases and does not recover until 2 to 3 wk after calving (Kehrli et al., 1989). The sudden demand for $\mathrm{Ca}$ at parturition often results in subclinical or clinical hypocalcemia. Subclinical hypocalcemia $(\mathbf{S C H})$ is a common disease found to affect approximately $50 \%$ of multiparous animals and $25 \%$ of primiparous animals (Reinhardt et al., 2011). Subclinical hypocalcemia is associated with decreased PMN function, reduced DMI and milk yield, decreased odds of pregnancy at first AI, and increased risk of transition disorders, including displaced abomasum and metritis (Chapinal et al., 2011, 2012; Martinez et al., 2012; Martinez et al., 2014). Calcium plays an important role in immune cell function. An increase in cytosolic $\mathrm{Ca}$ is associated with PMN activation and function (Bréchard and Tschirhart, 2008). Leukocytes from cows with hypocalcemia have decreased intracellular Ca storage and reduced Ca release from intracellular stores after activation leading to a blunted Ca response to activation (Kimura et al., 2006). Calcium diffusion from extracellular fluid and intracellular stores may be the rate-limiting step in triggering cytoplasmic flux of Ca (Schaff et al., 2008). 
Effective treatment and control of hypocalcemia is critical on a dairy farm. Feeding a low-DCAD diet in pre-fresh rations is common practice to increase available $\mathrm{Ca}$ and prevent clinical and subclinical hypocalcemia (USDA NAHMS, 2014). The combination of feeding an acidogenic diet prepartum with administration of an oral Ca bolus at calving appears to be more effective at reducing $\mathrm{SCH}$ than implementing just one or the other (Afshar Farnia et al., 2018). Oral Ca boluses are often used to raise Ca levels around calving and prevent hypocalcemia. Recent studies have found differential effects among populations of primiparous and multiparous cows. Positive responses to 2 doses of oral Ca boluses containing $43 \mathrm{~g}$ given $24 \mathrm{~h}$ apart were limited to animals with high previous lactation milk yield and lame cows (Oetzel and Miller 2012). Calcium bolus supplementation increased milk production at first test in multiparous cows that had high previous lactation milk yield and decreased incidences of health events in lame cows. A single dose of 54 to 64 $\mathrm{g}$ of $\mathrm{Ca}$ in primiparous and multiparous animals led to improvements in health status, including reduced risk of retained placenta and displaced abomasum in multiparous animals with low plasma Ca concentration at calving, but had no effect on Ca status as a whole in primiparous animals (Leno et al., 2018). However, in that study primiparous animals over $712 \mathrm{~d}$ old supplemented with $\mathrm{Ca}$ boluses had decreased risk of developing one or more health disorders. Further, Ca-supplemented primiparous animals that either had gestation length greater than $277 \mathrm{~d}$ or that were overconditioned $(>3.5$ BCS) had an increase in milk production. Calcium boluses containing $86 \mathrm{~g}$ of $\mathrm{Ca}$ given at calving and 24 $\mathrm{h}$ later, $86 \mathrm{~g}$ at calving followed by $43 \mathrm{~g} 24 \mathrm{~h}$ later, or $86 \mathrm{~g}$ of Ca at calving followed by $43 \mathrm{~g}$ on d 2 to 4 , reduced incidences of subclinical hypocalcemia on $\mathrm{d} 0$ and 1 in all cows (Martinez et al., 2016). However, with regard to health variables, primiparous animals did not respond favorably to the Ca bolus supplementation. In that study, primiparous animals supplemented with $\mathrm{Ca}$ had a rebound in $\mathrm{SCH}$ on d 2 and 4, and bolus supplementation led to an increase in metritis. The results of this study led the authors to conclude that large doses of oral $\mathrm{Ca}$ in the first days postpartum should be avoided in primiparous cows and used only in cows at risk for clinical hypocalcemia.

The objectives of this study were (1) to characterize intracellular PMN Ca dynamics and PMN function in primiparous and multiparous animals following oral $\mathrm{Ca}$ bolus supplementation and (2) to determine whether a lower dose of oral $\mathrm{Ca}$ in primiparous animals had positive effects on intracellular PMN Ca and function. The first hypothesis was that an oral Ca bolus given on the day of calving and $24 \mathrm{~h}$ later would increase intracellular PMN Ca and increase PMN function. The second hypothesis was that giving $25 \mathrm{~g}$ of oral $\mathrm{Ca}$ to primiparous animals would increase intracellular PMN $\mathrm{Ca}$ and PMN function to the same degree as $50 \mathrm{~g}$ of oral $\mathrm{Ca}$ but limit any potential adverse interference with initiating homeorhetic mechanisms that regulate Ca metabolism in early lactation.

\section{MATERIALS AND METHODS}

\section{Study Design}

Objective 1 was designed as a block randomized study to examine the effects of $50 \mathrm{~g}$ of oral Ca bolus versus no Ca bolus in multiparous and primiparous animals. Objective 2 was to characterize a dose response of $25 \mathrm{~g}$ and $50 \mathrm{~g}$ of an oral $\mathrm{Ca}$ bolus versus no $\mathrm{Ca}$ in primiparous animals only. The primiparous animals supplemented with $50 \mathrm{~g}$ to test the hypotheses in objective 2 were the same primparious animals used to test the hypotheses in objective 1 . The minimum sample size required to have $5 \%$ and $80 \%$ protection against type I and II errors, respectively, with an effect size difference in any variable of $15 \%$ increase with a coefficient of variation of $15 \%$ was 15 animals. We enrolled a minimum of 20 animals per treatment group to account for any lost animals or increase in the sample variation. The study was conducted over a 20-d period. Objective 1 involved 83 primiparous and multiparous animals, and objective 2 included 64 primiparous animals. Treatments in objective 1 included a control group (CON) with no oral Ca bolus supplementation $(\mathrm{n}=42)$, or a Ca bolus containing $50 \mathrm{~g}$ of $\mathrm{Ca}(\mathrm{n}=41)$. Objective 2 treatments included a CON group with no oral Ca supplementation $(\mathrm{n}=22)$, or an oral $\mathrm{Ca}$ bolus containing $25 \mathrm{~g}$ $(\mathrm{n}=21)$ or $50 \mathrm{~g}(\mathrm{n}=21)$ of oral $\mathrm{Ca}$ as a bolus. All cows enrolled completed the study protocol and were included in the final analysis. Cows assigned to receive a bolus regardless of $\mathrm{Ca}$ dose were given a series of 2 boluses, with the first bolus administered at enrollment (within $24 \mathrm{~h}$ of parturition), and the second bolus 24 $\mathrm{h}$ later. Boluses were composed of a mixture of calcium chloride, calcium sulfate, and calcium propionate (FreshCal) prepared by MB Nutritional Sciences in Lubbock, Texas. All treatments were administered by research personnel. Only cows that calved within $24 \mathrm{~h}$ of parturition, as indicated by the dairy's records, were eligible for enrollment in the study. Upon arrival of staff at the dairy farm at $0730 \mathrm{~h}$ each day, cows that had calved in the past $24 \mathrm{~h}$ were blocked by time relative to calving (0-8 h, 9-16 h, and 17-24 h) and randomly assigned to treatment. A random treatment enrollment list was created for each block before initiating the study, and animal identification numbers in each 
block were randomly chosen and sequentially assigned to the next treatment in that block. All cows received a BCS at enrollment, using a 1-to 5-point scale with 0.25 increments (Ferguson et al., 1994). Two trained observers blinded to treatment gave individual BCS for each cow, and when scores did not align, the observers discussed the score together to come to agreement. Blood samples were collected from all animals by puncture of the coccygeal vessels on $\mathrm{d} 1(<24 \mathrm{~h}), 2,3,5$, and 7 relative to calving.

\section{Cow Selection and Housing}

This study was conducted on a commercial dry-lot dairy farm milking 3,500 cows in West Texas from August until September of 2018. Primiparous and multiparous animals were moved to the close-up pen at approximately 243 and $250 \mathrm{~d}$ of gestation, respectively. Primiparous and multiparous animals were housed together in the close-up pen. Animals calved in the close-up pen, and calves were immediately separated from dams at parturition. All animals were first milked at calving in the maternity barn before being moved to a small fresh pen with all animals that had calved within the previous $24 \mathrm{~h}$. All animals in the small fresh pen were milked at $0500 \mathrm{~h}$ and $1400 \mathrm{~h}$, after which they were moved to the fresh pen. Primiparous and multiparous fresh cows were housed together in the fresh pen. The fresh pen had 320 headlocks and contained an average of 250 animals. Animals in the fresh pen were milked twice daily at $0830 \mathrm{~h}$ and $2030 \mathrm{~h}$. All animals were Jersey $\times$ Holstein crossbreds.

\section{Diets}

The formulated and nutrient compositions of the prepartum and fresh cow rations are presented in Table 1. Prepartum primiparous and multiparous animals were fed an acidogenic TMR once daily with DCAD of -18 $\mathrm{mEq} / 100 \mathrm{~g}$ of DM, where DCAD $=\left(\left[\mathrm{Na}^{+}\right]+\left[\mathrm{K}^{+}\right]\right)-$ $\left(\left[\mathrm{Cl}^{-}\right]+\left[\mathrm{S}^{2-}\right]\right)$. Animals in the fresh pen were fed twice daily, in the morning and afternoon. The a.m. feeding was delivered after the bunk was cleaned out and while cows were in the parlor, so that cows returned from the parlor to fresh feed. Employees pushed up feed throughout the day and night hourly as needed.

\section{Blood Samples}

Two blood samples $(3 \mathrm{~mL}$ with sodium heparin and $6 \mathrm{~mL}$ with no additive) were taken on $1(<24 \mathrm{~h}$ of parturition), 2, 3, 5, and 7 DIM when the animals returned from the milking parlor in the morning. Serum was collected from the evacuated tube with no additive after being allowed to clot at room temperature for 30 min and centrifuged for $15 \mathrm{~min}$ at $23^{\circ} \mathrm{C}$ and $1,500 \times \mathrm{g}$. Serum was analyzed for total Ca and haptoglobin. The sodium heparin evacuated tube was analyzed within 3 $\mathrm{h}$ of collection and used to measure surface expression of L-selectin on PMN, intracellular Ca of PMN, and phagocytic and oxidative burst capacities of PMN.

\section{Serum Total Ca}

Serum total Ca was determined using a commercially available enzymatic kit based on Arsenazo III dye [Total Ca LiquiColor (Arsenazo III) Procedure No. 0155,

Table 1. Ingredient and nutrient composition of prepartum and postpartum diets, DM basis

\begin{tabular}{|c|c|c|}
\hline \multirow[b]{2}{*}{ Item } & \multicolumn{2}{|c|}{ Diet } \\
\hline & Prepartum $^{1}$ & Postpartum $^{2}$ \\
\hline \multicolumn{3}{|l|}{ Ingredient, $\%$ of diet DM } \\
\hline Alfalfa hay & - & 2.91 \\
\hline Grass hay & 28.57 & - \\
\hline Corn silage & - & 33.41 \\
\hline Wheat silage & 28.57 & 8.35 \\
\hline Soybean meal & 8.33 & 5.13 \\
\hline Corn gluten feed & 5.31 & 10.19 \\
\hline Ground corn & 12.45 & 17.04 \\
\hline Cottonseed & - & 7.21 \\
\hline NovaMeal $^{3}$ & - & 5.13 \\
\hline Wet distillers grain & 10.61 & - \\
\hline Whey & - & 3.58 \\
\hline Blood meal & - & 2.05 \\
\hline Prepartum minerals $^{4}$ & 6.16 & - \\
\hline Postpartum minerals ${ }^{5}$ & - & 4.99 \\
\hline \multicolumn{3}{|l|}{ Nutrient profile } \\
\hline DM, $\%$ & 54.7 & 52.8 \\
\hline $\mathrm{NE}_{\mathrm{L}}, \mathrm{Mcal} / \mathrm{kg}$ & 0.65 & 0.77 \\
\hline Starch, \% & 20.4 & 28.0 \\
\hline $\mathrm{CP}, \%$ & 12.9 & 15.8 \\
\hline NDF, $\%$ & 38.4 & 27.8 \\
\hline $\mathrm{ADF}, \%$ & 29.1 & 18.7 \\
\hline $\mathrm{Ca}, \%$ & 1.12 & 1.39 \\
\hline $\mathrm{P}, \%$ & 0.33 & 0.31 \\
\hline $\mathrm{Mg}, \%$ & 0.66 & 0.44 \\
\hline $\mathrm{K}, \%$ & 0.97 & 1.26 \\
\hline $\mathrm{Na}, \%$ & 0.14 & 0.55 \\
\hline $\mathrm{Cl}, \%$ & 0.96 & 0.59 \\
\hline $\mathrm{S}, \%$ & 0.36 & 0.21 \\
\hline $\mathrm{DCAD},{ }^{6} \mathrm{mEq} / \mathrm{kg}$ & -18.2 & 26.2 \\
\hline
\end{tabular}

${ }^{1}$ Last $21 \mathrm{~d}$ of gestation.

${ }^{2}$ First $21 \mathrm{~d}$ after parturition.

${ }^{3}$ Rumen bypass protein (Novita Nutrition, Brookings, SD).

${ }^{4}$ Prepartum minerals contain (DM basis) $5.3 \%$ vitamins A, D, and $\mathrm{E}$ concentrate, $49.0 \%$ Animate (Phibro Animal Health Corp., Teaneck, NJ), and 9.9\% MagOx (Premier Magnesia, Waynesville, NC).

${ }^{5}$ Postpartum minerals contain (DM basis): $2.7 \%$ vitamins A and D, $0.2 \%$ Rumensin (Elanco, Greenfield, IN), 14.4\% MagnaPac (Norel, Madrid, Spain), 1.4\% MagOx (Premier Magnesia), 0.5\% Smartamine (Addiseo, Antony, France), 0.5\% Mintrex Dairy 2.0 (Novus, Saint Charles, MO), and 0.5\% Mintrex Zn (Novus).

${ }^{6}$ Calculated using the equation $\mathrm{DCAD}=[(\mathrm{Na}, \%$ of DM$/ 0.023)+(\mathrm{K}$, $\%$ of DM/0.039) $]-[(\mathrm{S}, \%$ of DM/0.016) $+(\mathrm{Cl}, \%$ of DM/0.0355) $]$. 
Stanbio Labs, Hampton, NH]. Ten microliters of serum or standard was mixed with $1 \mathrm{~mL}$ of reagent, vortexed, and incubated for $1 \mathrm{~min}$ at $23^{\circ} \mathrm{C}$, and then $200 \mu \mathrm{L}$ was transferred to a 96-well plate. Absorbance at 650 $\mathrm{nm}$ was read using a SpectraMax spectrophotometer (Molecular Devices, San Jose, CA). The intra- and interassay coefficients of variation were 2.2 and $3.5 \%$, respectively.

\section{PMN Intracellular Ca}

Basal and Escherichia coli-stimulated cytosol-ionized $\mathrm{Ca}^{2+}$ responses were measured using Fluo-4-acetoxymethyl (AM) ester (Fluo-4) emission, which increases with greater cytosol-ionized $\mathrm{Ca}$ concentration. One hundred microliters of whole blood samples from heparinized tubes were aliquoted into low-adhesion microcentrifuge tubes in duplicate to create basal and E. colistimulated groups. All samples were placed on ice for 15 min to minimize cellular activity. A stock solution of Fluo-4 dye $(1,000 \mu M)$ was made by adding dimethyl sulfoxide to a vial of freeze-dried Fluo-4 (Invitrogen, Carlsbad, CA). Contents were pipetted up and down 10 times to reconstitute and stored at $-20^{\circ} \mathrm{C}$ for up to $7 \mathrm{~d}$. The Fluo- 4 dye was diluted to a working concentration of $6 \mu M$ in $1 \times$ PBS with Pluronic F127 (Sigma-Aldrich, Saint Louis, MO) at a final concentration of $0.12 \%$. Ten microliters of working Fluo-4 AM dye was added to each sample (basal and stimulated). Samples were vortexed and incubated in a recirculating water bath for exactly $30 \mathrm{~min}$ at $38.5^{\circ} \mathrm{C}$ to load the Fluo- 4 dye into leukocytes. All samples were immediately placed in an ice bath to limit any further cellular activity. After 15 min in the ice bath, the E. coli-stimulated samples had $20 \mu \mathrm{L}$ of a heat-killed environmental E. coli, isolated from a cow with clinical mastitis, added (concentration of bacterial working solution approximately $10^{9} \mathrm{cfu} /$ $\mathrm{mL})$. Stimulated samples were vortexed and returned to the water bath at $38.5^{\circ} \mathrm{C}$ for exactly 2 min, whereas the basal samples were kept on ice. The stimulated samples were immediately placed on ice for another 15 min. All samples were then hypotonically lysed for $30 \mathrm{~s}$ with $800 \mu \mathrm{L}$ of ice-cold water and returned to isotonic conditions with $200 \mu \mathrm{L}$ of ice-cold $5 \times$ PBS. Samples were then centrifuged for $5 \mathrm{~min}$ at $4^{\circ} \mathrm{C} 1,200 \times g$, and the supernatant was aspirated. Samples were washed 2 times with ice-cold $1 \times$ PBS. The remaining pellet was reconstituted in $1 \mathrm{~mL}$ of ice-cold $1 \times \mathrm{PBS}$ and remained in a covered ice bath until it was analyzed on an Attune NxT flow cytometer (Invitrogen) within $1 \mathrm{~h}$. The PMN population was differentiated based on forward and side scatter characteristics. The geometric mean fluorescence intensity of the first fluorescence chan- nel (FL-1, 515 to $535 \mathrm{~nm}$ ) was used to quantify the cytosol-ionized $\mathrm{Ca}$ in each sample.

\section{Serum Haptoglobin}

Serum haptoglobin concentrations were measured via quantification of the haptoglobin/hemoglobin complex by estimation of differences in peroxidase activity, as described by (Makimura and Suzuki, 1982). Twentyfive microliters of methemoglobin were added to each borosilicate glass tube. Then $5 \mu \mathrm{L}$ of either distilled water (negative control), known serum standard, or unknown serum samples were added to each tube and vortexed. Next, $7.5 \mathrm{~mL}$ of O-dianisidine buffer was added to each tube, vortexed, and incubated at $37^{\circ} \mathrm{C}$ in a water bath for $45 \mathrm{~min}$. After removal from the water bath, $100 \mu \mathrm{L}$ of $156 \mathrm{~m} M$ hydrogen peroxide was added to each tube, and tubes were vortexed and incubated at room temperature in the dark for $1 \mathrm{~h}$. Finally, $200 \mu \mathrm{L}$ of sample from each tube was pipetted into a 96-well plate and read in the SpectraMax (Molecular Devices, Carlsbad, CA) at $450 \mathrm{~nm}$. Data were converted from an optical density to micrograms per milliliter by creating a regression equation from serum samples with known concentrations. The interassay plate coefficients of variation for low and high pooled serum haptoglobin controls were $14.5 \%$ and $8.2 \%$, respectively. Intra-assay coefficient of variation was $6.2 \%$.

\section{PMN Surface L-Selectin Analysis}

One hundred microliters of blood were pipetted into a low-adhesion microcentrifuge tube from heparinized evacuated tubes that were inverted for $5 \mathrm{~min}$ on a rocker. A primary antibody (Clone \#BAQ92A, Washington State University Monoclonal Antibody Center, Pullman, WA) was diluted to a working solution 1:100 in $1 \times$ PBS. All samples received $100 \mu \mathrm{L}$ of the primary antibody and were vortexed and placed on ice for $1 \mathrm{~h}$. After $30 \mathrm{~min}$, the samples were vortexed and placed back on ice for an additional $30 \mathrm{~min}$. Red blood cells were hypotonically lysed with $800 \mu \mathrm{L}$ of ice-cold water and inverted for $30 \mathrm{~s}$ before adding $200 \mu \mathrm{L}$ of ice-cold $5 \times$ PBS, which was inverted for $15 \mathrm{~s}$. Samples were then centrifuged at $1,200 \times g$ and $4^{\circ} \mathrm{C}$ for $5 \mathrm{~min}$. The supernatant was aspirated, and samples were washed an additional 2 times with ice-cold PBS. One hundred microliters of the secondary antibody, fluoresceinlabeled secondary antibody $\left[\mathrm{F}\left(\mathrm{ab}^{\prime}\right) 2\right.$ anti-mouse IgG: FITC; AbD Serotec, Raleigh, NC], at a working dilution of 1:400 in $1 \times$ PBS was added to each sample, and samples were vortexed and incubated on ice for 1 h. After $30 \mathrm{~min}$, the samples were vortexed and placed 
back on ice for an additional $30 \mathrm{~min}$. Then samples were rinsed twice with $1 \mathrm{~mL}$ of ice-cold $1 \times$ PBS, vortexed, and centrifuged at $1,200 \times g$ and $4^{\circ} \mathrm{C}$ for $5 \mathrm{~min}$, and supernatant was aspirated. Finally, $1 \mathrm{~mL}$ of ice-cold $1 \times$ PBS was added to all samples, and samples were analyzed on an Attune NxT flow cytometer (Invitrogen) within $1 \mathrm{~h}$. The PMN population was gated based on forward and side scatter characteristics. The geometric mean florescence intensity of the FL-1 channel (515 to $535 \mathrm{~nm}$ ) was used to quantify expression of FITC fluorochrome.

\section{PMN Phagocytosis and Oxidative Burst}

Polymorphonuclear leukocyte phagocytosis and oxidative burst capacities in response to an environmental E. coli isolated from a cow with mastitis were determined. Whole blood from the heparinized tube was gently inverted for 5 min on a rocker. Then, 100 $\mu \mathrm{L}$ of blood sample was pipetted into low-adhesion microcentrifuge tubes and placed on ice for $15 \mathrm{~min}$. A propidium iodide-labeled, heat-killed E. coli bacteria with a bacterial concentration of $10^{9} \mathrm{cfu} / \mathrm{mL}$ was removed from a $-80^{\circ} \mathrm{C}$ freezer and allowed to thaw. A working solution of dihydrorhodamine (1:50) was made each day by diluting a stock solution with $1 \times$ PBS. Twenty microliters of dihydrorhodamine and 20 $\mu \mathrm{L}$ of the working concentration of $E$. coli were added to each sample. Samples were vortexed and placed in a recirculating water bath at $38.5^{\circ} \mathrm{C}$ for exactly $10 \mathrm{~min}$ before being removed and placed on ice for $15 \mathrm{~min}$. All samples were then lysed for $30 \mathrm{~s}$ with $800 \mu \mathrm{L}$ of ice-cold water to hypotonically lyse the red blood cells. This step was followed by the addition of $200 \mu \mathrm{L}$ of ice-cold $5 \times$ PBS to all samples. Samples were centrifuged for $5 \mathrm{~min}$ at $1,200 \times g$, and supernatant was aspirated. Hypotonic lysis with water, $5 \times$ PBS, centrifuge, and aspiration steps were repeated once more before adding $1 \mathrm{~mL}$ of ice-cold PBS. Samples were then analyzed on a flow cytometer. To determine the ability of PMN populations to phagocytose and produce an oxidative burst, PMN populations were gated based on forward and side scatter characteristics. The percentage of PMN positive for both phagocytosis and oxidative bursts was determined as cells that had FL-1 and FL-3 fluorescence greater than the appropriate negative controls for each fluorescence channel. Further, the geometric mean fluorescence intensities of the FL-1 (515 to 535 $\mathrm{nm})$ and FL-3 channels $(\geq 675)$ in the double positive for both phagocytosis and oxidative burst were used to quantify the intensity of expression of rhodamine (oxidative burst) and propidium iodide (phagocytosis), respectively. The negative control for the FL-1 channel was PMN-incubated with dihydrorhodamine, similar to the samples, but without the addition of any PIlabeled E. coli. The negative control for the FL-3 channel was PMN-incubated with the PI-labeled $E$. coli but remained in the ice bath during the 10 min water bath incubation.

\section{Health and Production}

Milk production was recorded weekly for the first 21 wk in milk each Saturday by measuring the milk weight of each cow during the a.m. and then multiplying by 2. Identification of each cow at milking was performed by research personnel, and the milk production per cow was measured using an MC 200 SCR milking control system (Allflex, Dallas, TX). Incidences of mastitis and metritis were determined by herd personnel and recorded in Dairy Comp 305 (Valley Ag Software, Visalia, CA). Incidences of each disease are reported for each cow. Following a 50-d voluntary waiting period, all animals were eligible to be bred. Data are reported for each cow as either pregnant or open at 150 DIM.

\section{Statistical Analysis}

All repeated, continuous data were analyzed by restricted-maximum likelihood ANOVA using the Mixed procedure of SAS (version 9.4; SAS Institute Inc., Cary, NC). The statistical model to determine the interaction between parity and $50 \mathrm{~g}$ of oral $\mathrm{Ca}$ included the fixed effects of treatment (0 vs. $50 \mathrm{~g}$ of oral Ca), parity (primiparous vs. multiparous), DIM, and all interactions. The statistical model to determine whether the dose response effect of oral $\mathrm{Ca}$ among primiparous cows included only the fixed effects of treatment $(0$, 25 , and $50 \mathrm{~g}$ of oral Ca), DIM, and treatment $\times$ DIM. Covariates tested included baseline values $(\mathrm{DIM}=1)$ for each dependent variable, BCS, and gestation length in days. Neither BCS nor gestation length were significant; therefore, they were removed from all the models. Baseline values remained in the model even if they were not significant. Block (time relative to calving) was treated as a random effect in all models. The subject of the repeated statement was animal nested within treatment. Each model was run with all available covariance structures with unequal time spacing for the withinanimal measurement. The appropriate covariance and variance structures were chosen for each analysis based on the smallest Schwarz Bayesian information criterion. Serum haptoglobin data were converted to an area under the curve (AUC) using the trapezoidal rule before statistical analysis; therefore, those models did not include DIM as a fixed effect. Normality of the residuals in the final models were confirmed by evaluating the Shapiro-Wilk statistic and normal probability plots of 
the residuals using the Univariate procedure of SAS. Pairwise comparisons were made for each significant effect using a Tukey adjustment. Further, orthogonal linear and quadratic contrasts as well as a pre-planned contrast [Con vs. $(25 \mathrm{~g}+50 \mathrm{~g}) / 2$ ] were also used to test treatment differences. Statistical significance was declared at $P \leq 0.05$, and a tendency was considered if $0.10 \leq P>0.05$. Data are presented as least squares means \pm the standard error of the mean.

All binary data were analyzed using the Glimmix procedure of SAS. The statistical model to determine the interaction between parity and $50 \mathrm{~g}$ of oral $\mathrm{Ca}$ included the fixed effects of treatment, parity (primiparous vs. multiparous), and treatment $\times$ parity. The statistical model to determine the dose response effect of oral Ca among primiparous animal included only the fixed effect of treatment. The binary distribution was used with logit link function. Block (time relative to calving) was treated as a random effect in all models. Statistical significance was declared at $P \leq 0.05$, and a tendency was considered if $0.10 \leq P>0.05$. Data are presented as proportions \pm the standard error of the mean as well as odd ratios with estimated $95 \%$ confidence intervals.

\section{RESULTS}

\section{Parity $\times$ Oral Ca (50 g)}

Descriptive percentages of animals with SCH using cut-points of both $2.05 \mathrm{mM}$ and $2.2 \mathrm{mM}$ are reported in Table 2. Serum total Ca and PMN intracellular Ca, both basal and when cocultured with E. coli, are reported in Table 3 . We detected no treatment $\times$ parity $\times \operatorname{DIM}(P \geq 0.757)$, treatment $\times$ parity $(P \geq 0.356)$, or treatment $\times$ DIM $(P \geq 0.591)$ effects on serum total Ca or either intracellular PMN Ca measurements. Further, no treatment difference $(P=0.906)$ was detectable on serum total Ca; however, a tendency $(P=0.078)$ occurred for a treatment difference on basal intracellular PMN Ca and a treatment difference $(P=0.017)$ on E. coli-stimulated intracellular PMN Ca. The $50 \mathrm{~g}$ of oral Ca bolus increased both basal and E. coli-stimulated intracellular PMN Ca. Primiparous animals had greater $(P=0.043)$ total serum Ca than multiparous animals. Further, we detected a parity $\times$ DIM effect $(P$ $=0.006$ ) on basal intracellular PMN Ca and a tendency $(P=0.100)$ on $E$. coli-stimulated intracellular PMN Ca (Figures $1 \mathrm{a}$ and $\mathrm{b}$ ).

Polymorphonuclear leukocyte surface L-selectin expression, PMN phagocytic and oxidative burst capacities in response to the E. coli, and serum haptoglobin AUC are reported in Table 3 . No treatment $\times$ parity $\times$ DIM $(P \geq 0.423)$, treatment $\times$ parity $(P \geq 0.205)$, treatment $\times \operatorname{DIM}(P \geq 0.585)$, or treatment $(P \geq$
$0.129)$ effects were detectable on any PMN variables or serum haptoglobin. A parity $\times$ DIM effect for PMN oxidative burst intensity (Figure 2) was detected; however, we found no other parity $\times \operatorname{DIM}(P>0.144)$ or parity $(P \geq 0.122)$ effects on other functional PMN variables. A parity difference $(P=0.001)$ occurred on serum haptoglobin AUC, whereas primiparous animals had greater haptoglobin AUC.

Milk production is reported in Table 3 . We found a parity $\times$ week of lactation effect $(P=0.006)$ on milk production but detected no treatment $\times$ week of lactation $(P=0.151)$, treatment $\times$ parity $(P=0.415)$, treatment $\times$ parity $\times$ week of lactation $(P=0.131)$, or treatment $(P=0.516)$ differences. Incidences of mastitis and metritis and proportion of animals confirmed pregnant at 150 DIM are reported in Table 4. No treatment $\times$ parity $(P \geq 0.509)$ or treatment $(P$ $\geq 0.136)$ effects were detected on any of the health or reproductive outcomes.

\section{Primiparous Dose Response}

Serum total $\mathrm{Ca}$ and PMN intracellular $\mathrm{Ca}$, both basal and when cocultured with $E$. coli, are reported in Table 5 . No treatment $\times$ DIM $(P \geq 0.539)$ effects were detectable on serum total $\mathrm{Ca}$ or on either intracellular PMN Ca measurement. Further, we found no treatment difference $(P=0.341)$ on serum total $\mathrm{Ca}$ or basal intracellular PMN Ca. However, a treatment difference $(P=0.005)$ was detectable for $E$. coli-stimulated intracellular PMN Ca among primiparous animals given 50 $\mathrm{g}$ of $\mathrm{Ca}$. The oral Ca bolus containing $50 \mathrm{~g}$ increased $E$. coli-stimulated intracellular PMN Ca.

Polymorphonuclear leukocyte surface L-selectin expression, PMN phagocytic and oxidative burst capacities in response to E. coli, and serum haptoglobin

Table 2. Percentage of primiparous (Primi) and multiparous (Multi) animals with subclinical hypocalcemia, determined as total serum calcium $\leq 2.2 \mathrm{~m} M$ and $\leq 2.05 \mathrm{~m} M^{1}$

\begin{tabular}{|c|c|c|c|c|c|}
\hline \multirow[b]{2}{*}{ Item } & \multicolumn{3}{|c|}{ Primi } & \multicolumn{2}{|c|}{ Multi } \\
\hline & $0 \mathrm{~g}$ & $25 \mathrm{~g}$ & $50 \mathrm{~g}$ & $0 \mathrm{~g}$ & $50 \mathrm{~g}$ \\
\hline $\begin{array}{l}\mathrm{n} \\
\mathrm{DIM}\end{array}$ & 22 & 21 & 21 & 20 & 20 \\
\hline 1 & $100(36)$ & $95(57)$ & $86(33)$ & $100(59)$ & $100(58)$ \\
\hline 2 & $86(27)$ & $81(29)$ & $80(40)$ & $96(46)$ & $95(53)$ \\
\hline 3 & $82(41)$ & $86(24)$ & $82(14)$ & $86(32)$ & 100 \\
\hline 5 & $77(23)$ & $76(33)$ & $71(33)$ & $82(27)$ & $84(32)$ \\
\hline 7 & $91(23)$ & $75(25)$ & $76(14)$ & $68(36)$ & $74(26)$ \\
\hline
\end{tabular}

${ }^{1}$ Parity $\times$ oral $\mathrm{Ca}(50 \mathrm{~g})$ effects: There were no treatment $\times$ parity $\times$ DIM, treatment $\times$ parity, treatment $\times$ DIM, or treatment difference for the cut points of $2.2 \mathrm{~m} M(P \geq 0.512)$ or $2.05 \mathrm{~m} M(P \geq 0.374)$. Primiparous dose response: There were no treatment $\times$ DIM or treatment difference for the cut point of $2.2 \mathrm{mM}(P \geq 0.619)$ or $2.05 \mathrm{mM}$ $(P \geq 0.448)$. 
A

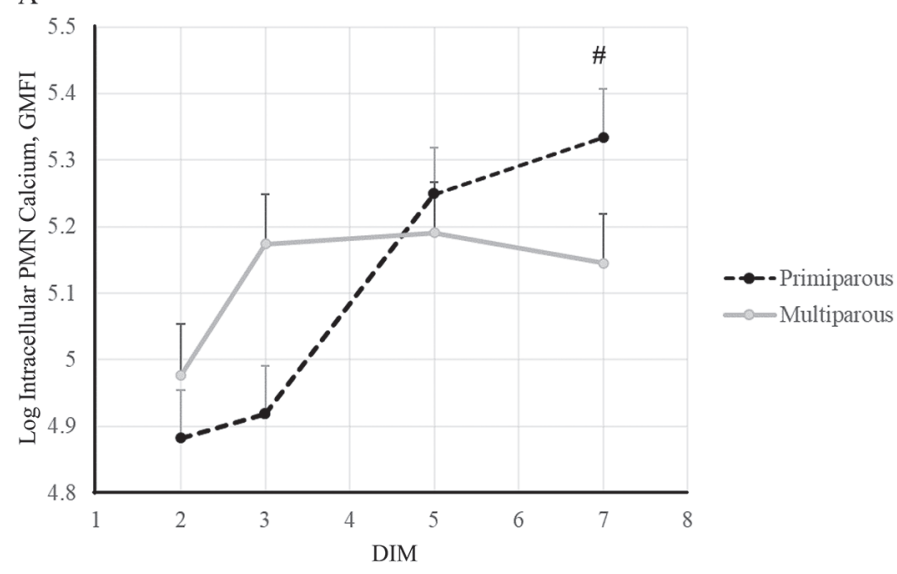

B

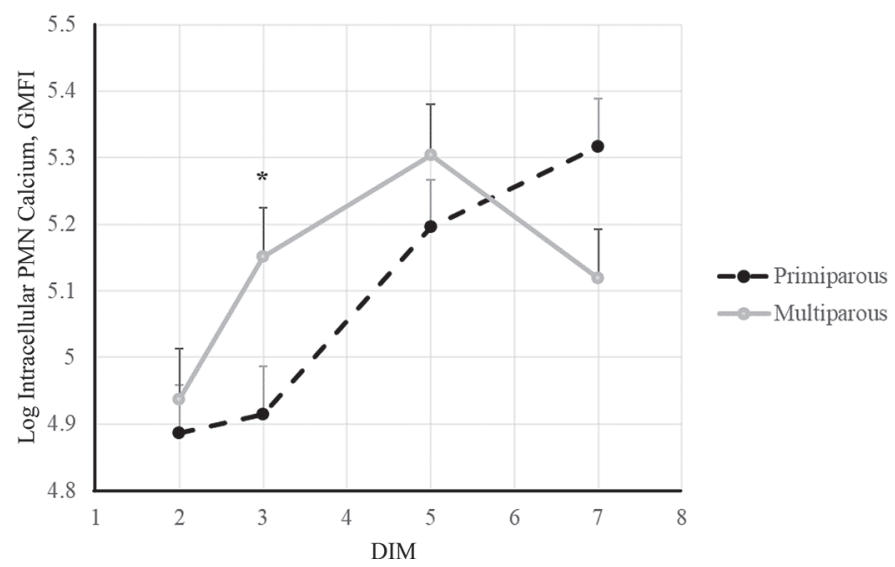

Figure 1. Parity effects on intracellular PMN Ca under (A) basal conditions, parity $\times \operatorname{DIM}(P=0.006)$; or $(B)$ Escherichia coli-stimulated conditions for 2 min, parity $\times$ DIM $(P=0.100)$. Data reported as $\log _{10}$-transformed LSM \pm SEM. Parity differences at each DIM shown as ${ }^{*} P \leq 0.05$ and $\# 0.05<P \leq 0.10$. GMFI $=$ geometric mean fluorescence intensity.

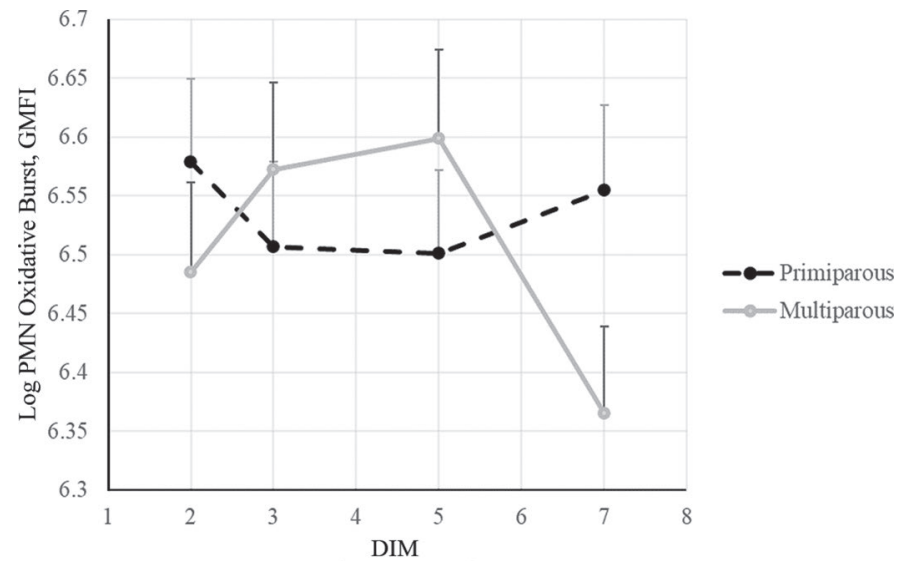

Figure 2. Parity $\times$ DIM effects on PMN oxidative burst intensity $(P=0.008)$. Data reported as $\log _{10}$-transformed LSM \pm SEM. GMFI $=$ geometric mean fluorescence intensity. 
Reitsma et al.: CALCIUM BOLUS NEUTROPHIL

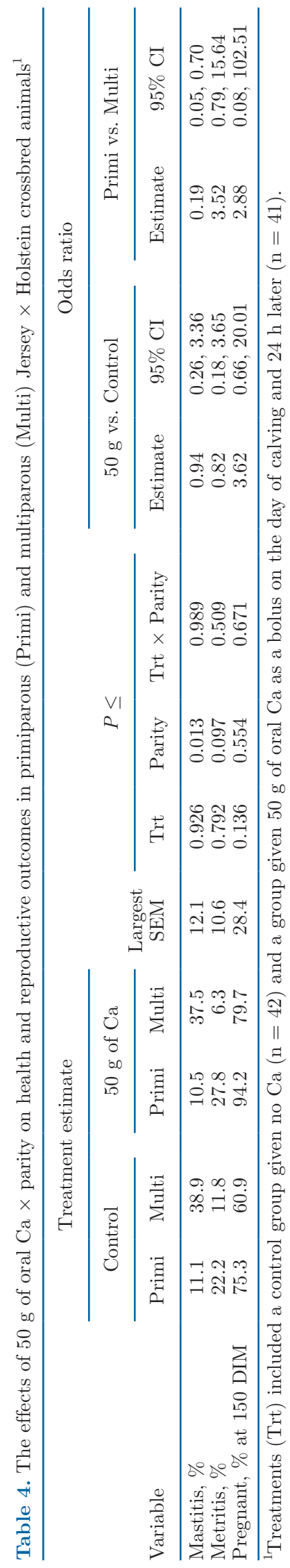

Journal of Dairy Science Vol. 103 No. 12, 2020

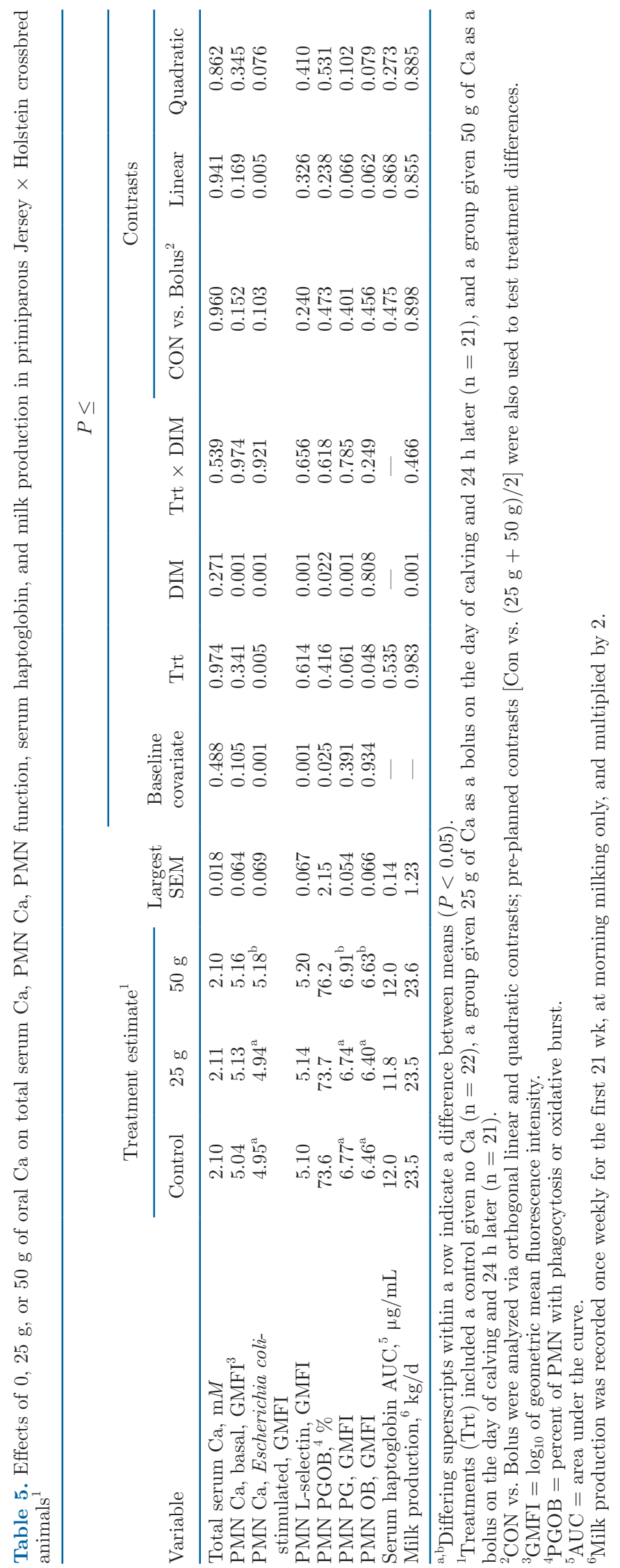


Table 6. Effects of 0, $25 \mathrm{~g}$, or $50 \mathrm{~g}$ of oral Ca on health and reproductive outcomes in primiparous Jersey $\times$ Holstein crossbred animals $^{1}$

\begin{tabular}{|c|c|c|c|c|c|c|c|c|c|}
\hline \multirow[b]{3}{*}{ Variable } & \multicolumn{3}{|c|}{ Treatment estimate } & \multirow{3}{*}{$\begin{array}{l}\text { Largest } \\
\text { SEM }\end{array}$} & \multirow{3}{*}{$\begin{array}{l}\text { Trt } \\
P \leq\end{array}$} & \multicolumn{4}{|c|}{ Odds ratio } \\
\hline & \multirow[b]{2}{*}{ Control } & \multirow[b]{2}{*}{$25 \mathrm{~g}$} & \multirow[b]{2}{*}{$50 \mathrm{~g}$} & & & \multicolumn{2}{|c|}{$25 \mathrm{~g}$ vs. Control } & \multicolumn{2}{|c|}{$50 \mathrm{~g}$ vs. Control } \\
\hline & & & & & & Estimate & $95 \% \mathrm{CI}$ & Estimate & $95 \% \mathrm{CI}$ \\
\hline Mastitis, \% & 11.1 & 5.5 & 10.5 & 7.4 & 0.822 & 0.47 & $0.04,6.07$ & 0.94 & $0.11,7.89$ \\
\hline Metritis, \% & 22.2 & 27.8 & 27.8 & 11.1 & 0.909 & 1.35 & $0.28,6.37$ & 1.35 & $0.28,6.37$ \\
\hline Pregnant, $\%$ at 150 DIM & 75.3 & 79.5 & 94.1 & 11.8 & 0.397 & 1.27 & $0.22,7.47$ & 5.04 & $0.46,55.16$ \\
\hline
\end{tabular}

${ }^{1}$ Treatments (Trt) included a control given no $\mathrm{Ca}(\mathrm{n}=22)$, a group given $25 \mathrm{~g}$ of $\mathrm{Ca}$ as a bolus on the day of calving and $24 \mathrm{~h}$ later $(\mathrm{n}=21)$, and a group given $50 \mathrm{~g}$ of $\mathrm{Ca}$ as bolus on the day of calving and $24 \mathrm{~h}$ later $(\mathrm{n}=21)$.

AUC are reported in Table 5. No treatment $\times$ DIM $(P \geq 0.656)$ or treatment $(P \geq 0.614)$ effects occurred on PMN surface L-selectin expression. No treatment $\times$ DIM $(P \geq 0.618)$ or treatment $(P \geq 0.416)$ effects were detectable on percentage of PMN positive for both phagocytosis and oxidative burst. We detected a treatment tendency $(P=0.061)$ for $50 \mathrm{~g}$ of oral Ca for PMN phagocytosis intensity. Primiparous animals receiving $50 \mathrm{~g}$ of oral $\mathrm{Ca}$ had greater PMN phagocytosis intensity than did primiparous animals that received $25 \mathrm{~g}$ of $\mathrm{Ca}$ or no oral Ca. A treatment difference $(P=$ 0.048 ) occurred for PMN oxidative burst intensity in primiparous animals given $50 \mathrm{~g}$ of oral Ca. Primiparous animals receiving $50 \mathrm{~g}$ of oral $\mathrm{Ca}$ had greater PMN oxidative burst than primiparous animals that received $25 \mathrm{~g}$ of $\mathrm{Ca}$ or no oral Ca. We found no treatment $(P=$ 0.535) effects on serum haptoglobin AUC.

Milk production is reported in Table 5 . We detected no treatment $\times$ week of lactation $(P=0.466)$ or treatment $(P=0.466)$ differences. Incidences of mastitis and metritis and proportion of animals confirmed pregnant at 150 DIM are reported in Table 6 . No treatment $(P$ $\geq 0.397$ ) effects were detectable on any of the health or reproductive outcomes.

\section{DISCUSSION}

This study investigated the effects of oral Ca boluses on intracellular PMN $\mathrm{Ca}$ and PMN function in primiparous and multiparous Jersey $\times$ Holstein crossbred cattle. This study also investigated a dose response of oral Ca on intracellular PMN Ca and PMN functionality among primiparous Jersey $\times$ Holstein crossbred cattle using a lower dose than recent studies. Data from both analyses indicate that oral Ca bolus supplementation did not affect total serum Ca. We detected a parity effect on total serum $\mathrm{Ca}$, indicating that primiparous animals had greater total serum Ca than multiparous animals, which is consistent with other data (Martinez et al., 2016; Wilhelm et al., 2017). Considering that primiparous animals are more likely to have greater $\mathrm{Ca}$ at calving, and too rapid a rise in serum Ca can lead to the activation of pathways aimed at decreasing serum $\mathrm{Ca}$, we hypothesized that a lower dose, $25 \mathrm{~g}$ of oral $\mathrm{Ca}$ as a bolus, would be more effective at raising serum Ca levels than $50 \mathrm{~g}$ of oral $\mathrm{Ca}$ in primiparous animals. However, the low dose of oral Ca was not more effective at increasing total serum $\mathrm{Ca}$ in primiparous animals throughout the first 7 DIM. Previous data reported that giving $20 \mathrm{~g}$ of $\mathrm{Ca}$ as a bolus from Ca propionate was effective in preventing milk fever (Pehrson et al., 1998). However, that study used 6 rather than 2 doses of oral Ca boluses, given at regular intervals between 36 and $24 \mathrm{~h}$ postpartum in multiparous cows that had experienced milk fever in the previous lactation.

Oetzel and Miller (2012) suggested that the acidogenic quality of calcium chloride may increase bone resorption and intestinal absorption of $\mathrm{Ca}$, thereby sustaining an increase in total serum Ca. The current study does not support this hypothesis, because total serum $\mathrm{Ca}$ after supplementation with either 25 or $50 \mathrm{~g}$ of $\mathrm{Ca}$ in the predominant form of calcium chloride was not affected by oral Ca supplementation. The timing of blood samples at $1,2,3,5$, and 7 DIM in the current study could explain why no difference was detected. In agreement, Blanc et al. (2014) found no significant effect of oral Ca bolus containing $43 \mathrm{~g}$ of $\mathrm{Ca}$ on total $\mathrm{Ca}$ concentrations at $24 \mathrm{~h}$ after supplementation. Further, the control cows in the study by Blanc et al. had greater total serum $\mathrm{Ca}$ than oral Ca-treated cows at $48 \mathrm{~h}$ after supplementation. Similarly, Melendez et al. (2004) found no significant effect of $60-\mathrm{g}$ Ca boluses on total Ca levels at 2, 3, 6, 9, and $12 \mathrm{~d}$ after parturition. After supplementation with oral $\mathrm{Ca}$, serum $\mathrm{Ca}$ increases rapidly before returning to baseline concentrations. Martinez et al. (2016) gave a single dose of 0 , 43 , or $86 \mathrm{~g}$ of $\mathrm{Ca}$ as an oral bolus to multiparous cows and observed a maximum change in ionized $\mathrm{Ca}$ at 0.5 $\mathrm{h}$ in both the 43- and 86-g treatments. Twenty-four hours after administration of 43 and $86 \mathrm{~g}$ of $\mathrm{Ca}$, ionized Ca returned to near-control concentrations. The largest increase in total serum $\mathrm{Ca}$ in that study was seen $1 \mathrm{~h}$ after supplementation in cows given $86 \mathrm{~g}$ of $\mathrm{Ca}$, but by $24 \mathrm{~h}$ total serum $\mathrm{Ca}$ was reduced near control concen- 
trations. Similarly, Valldecabres et al. (2018) reported a rapid increase in total serum $\mathrm{Ca}$ concentration at 1 $\mathrm{h}$ after supplementation with 50- to $60-\mathrm{g}$ oral Ca bolus but no treatment effect at 2 DIM. All of these studies, including the current study, used a Ca bolus composed primarily of highly soluble calcium chloride.

The Ca status on the day of calving has been shown to influence response to oral Ca bolus supplementation in multiparous Jersey cows (Valldecabres et al., 2018). In that study, SCH cows on the day of calving had a greater serum Ca concentration increase $1 \mathrm{~h}$ through 2 DIM after supplementation with oral Ca bolus than did SCH cows not given a Ca bolus. In contrast, normocalcemic animals treated with a bolus had a lower Ca concentration than did normocalcemic animals not treated with a bolus at 2 DIM, suggesting that the Ca supplementation in that study may have disrupted Ca homeorhetic mechanisms in normocalcemic cows. However, the baseline covariate data in the current study indicate that total serum Ca concentration at $\mathrm{d} 1 \mathrm{did}$ not influence the response to $\mathrm{Ca}$ bolus supplementation.

Data on $50 \mathrm{~g}$ of oral Ca bolus $\times$ parity indicated that bolus supplementation tended to increase PMN $\mathrm{Ca}$ in basal PMN and further increased PMN Ca when stimulated with $E$. coli. The parity $\times$ DIM effect for basal and E. coli-stimulated PMN Ca indicated that multiparous animals had greater numerical intracellular PMN Ca levels at 2 DIM and were greater at 3 DIM before dropping near 5 DIM, whereas primiparous animals started with lower intracellular PMN Ca at 2 and 3 DIM but numerically surpassed multiparous cows by 7 DIM. Considering the lower total serum $\mathrm{Ca}$ of multiparous cows compared with primiparous animals, these data indicate that PMN intracellular Ca flux depends on more than extracellular Ca concentrations during the periparturient period.

The primiparous oral Ca dose response data had a treatment effect for $50 \mathrm{~g}$ of $\mathrm{Ca}$ in the E. coli-stimulated PMN, but no treatment effect was observed for $25 \mathrm{~g}$ of Ca. Twenty-five grams of Ca may not have been enough to cause an increase in PMN intracellular Ca uptake. The quantity of highly soluble $\mathrm{Ca}$ in oral $\mathrm{Ca}$ boluses may be readily available for PMN to take up when intracellular stores are depleted. The exact mechanism of how an oral Ca bolus increases intracellular PMN Ca has not been fully elucidated. It could be that the expression of Ca channels on PMN increase after the administration of a Ca bolus or that the transient increase in extracellular Ca increases or replenishes Ca stores. Future studies focusing on the more immediate effects of bolus administration and uptake of intracellular PMN Ca would be beneficial to understanding the dynamics of intracellular PMN Ca uptake.
Although $50 \mathrm{~g}$ of oral Ca supplementation caused an overall increase in PMN Ca, the stimulated PMN intracellular $\mathrm{Ca}$ was similar to values of basal intracellular Ca. In resting cells, the majority of Ca is stored in the endoplasmic reticulum, and cytosolic levels are maintained at low levels by several Ca pumps. Engagement of cell surface receptors leads to release of $\mathrm{Ca}$ from the endoplasmic reticulum, followed by sustained influx of extracellular ionized $\mathrm{Ca}$ across the plasma membrane via $\mathrm{Ca}$ channels. The sustained influx of ionized $\mathrm{Ca}$ to the cytosol leads to the activation of molecules that mediate immune effector functions of PMN, including phagocytosis and oxidative burst (Bréchard and Tschirhart, 2008). Intracellular PMN Ca influx after stimulus may follow the pattern of total serum Ca after Ca bolus supplementation, where levels quickly rise before returning to baseline values. The Ca uptake by PMN after stimulation appears to be a quick process. The timing of incubation of leukocytes with an activating agent may explain why we did not see a difference in stimulated versus nonstimulated cells. In the present study, PMN were incubated with $E$. coli for $2 \mathrm{~min}$ to allow for activation of the cell and Ca influx. In human PMN, Schaff et al. (2008) imaged the real-time Ca flux of human PMN rolling on E-selectin in a microfluidic chamber. They activated PMN with IL- 8 and saw a peak in intracellular $\mathrm{Ca}$ at $10 \mathrm{~s}$, but by 1 min intracellular Ca began to decrease toward baseline levels. It could be that by measuring at $2 \mathrm{~min}$, the peak in intracellular PMN Ca was missed. However, Martinez et al. (2014) measured intracellular PMN Ca in nonlactating, nonpregnant cows at basal conditions and for $11 \mathrm{~min}$ following ionomycin stimulation. Those authors did not report the time that it took to reach peak intracellular PMN Ca levels, but by 11 min the levels had decreased. Kimura et al. (2006) activated peripheral mononuclear cells of multiparous dairy cows with anti-CD3 antibodies plus secondary antibodies and measured intracellular Ca release from intracellular stores after 5 to 6 min. They observed an increase in peripheral blood mononuclear cell Ca flux in response to stimulation by anti-CD3 mAb-secondary Ab complex in animals that were treated with an intravenous infusion of Ca. Their longer incubation time of 5 to 6 min could be because lymphocytes respond more slowly than PMN.

Low availability of both intracellular and extracellular Ca may be another explanation for the similarities in basal and stimulated intracellular PMN Ca levels in the current study. Ionized Ca plays an important role in the activation of leukocytes by acting as essential second messengers in signal transduction (Gronski et al., 2009). In the days surrounding calving, ionized and total serum Ca levels drop. Intracellular PMN Ca may follow this pattern. Our preliminary work indicates 
that fresh cows have lower intracellular PMN Ca than dry cows. The preliminary data suggested that a dry cow may have twice the intracellular PMN Ca than a fresh cow. Schaff et al. (2008) suggested that Ca diffusion from extracellular fluid and intracellular stores are the rate-limiting steps in triggering cytoplasmic flux of Ca. The low intracellular PMN Ca and the fact that ionized $\mathrm{Ca}$ is low surrounding calving may blunt the ability of PMN from fresh animals to respond to a stimulus. Kimura et al. (2006) found that intracellular Ca released in response to the activation signal declined as Ca demand for lactation became more intense and recovered as plasma Ca normalized. The animals in this study may not have had enough extracellular Ca available for PMN Ca influx. Under normal circumstances, total serum $\mathrm{Ca}$ is regulated to remain in a range from 2.25 to $2.75 \mathrm{mM}$ (Littledike et al., 1987). Average total serum Ca concentrations throughout the first 7 DIM for all animals ranged between 2.02 and $2.11 \mathrm{mM}$. Recent studies have suggested that the threshold used to define $\mathrm{SCH}$ should be raised from the more commonly used $2 \mathrm{~m} M$ to a greater value. Chapinal et al. (2012) found that cows with $<2.1 \mathrm{~m} M$ total serum $\mathrm{Ca}$ in the first 3 wk of lactation gave less milk than cows with greater $\mathrm{Ca}$, and cows with $<2.2 \mathrm{mM}$ total serum Ca were associated with reduced conception at first insemination. Additionally, Martinez et al. (2012) saw a reduction in PMN function in animals with serum Ca concentrations below $2.15 \mathrm{~m} M$ in the first $3 \mathrm{~d}$ postpartum. The average total serum Ca concentrations observed in the current study may explain why stimulated and basal PMN did not differ in intracellular Ca influx. It could be that stimulated PMN from the animals in this study did not have enough extracellular Ca available for intracellular Ca influx. Alternatively, the lack of a substantial increase in intracellular $\mathrm{Ca}$ influx when stimulated with $E$. coli in the present study could be due to the phagocytic stimuli. Ducusin et al. (2003) reported that intracellular neutrophil calcium increased to a greater degree when stimulated with opsonized zymosan than when stimulated nonspecifically with phorbol myristate acetate.

The exact role that calcium plays in the PMN function of periparturient animals remains to be fully determined. Bryant (1969) reported that many human neutrophil phagocytic responses to opsonized Staphylococcus aureus were impaired by Ca depletion. Further, O'Flaherty et al. (1977) reported that rabbit neutrophil aggregation was more sensitive to extracellular Ca concentrations than other neutrophil functions, including adherence, chemotaxis, degranulation, and phagocytosis. Neutrophil function in dairy cattle have also been reported to be dependent on Ca concentrations. Ducusin et al. (2003) reported that plasma Ca concen- trations were associated with intracellular neutrophil Ca in postpartum dairy cows. Neutrophil phagocytosis of fluorescent microspheres and intracellular neutrophil calcium in either resting or opsonized zymosan-stimulated were suppressed in both parturient paretic and nonparetic cows when extracellular Ca concentrations matched those of parturient paretic cows. Further, both the phagocytic and intracellular neutrophil Ca responses increased in both groups of cows when extracellular concentrations of the cultures were increased to the levels of nonparetic cows. More recently, Leno et al. (2017) determined that ionized $\mathrm{Ca}$ is consistently related to outcomes of PMN oxidative burst activity. Martinez et al. (2014) induced SCH in nonpregnant, nonlactating Holstein cows and observed that SCH cows had lower cytosolic ionized Ca in PMN than normocalcemic animals after stimulation with ionomycin. Those authors suggested that the decreased cytosolic ionized Ca was likely due to decreased influx from extracellular fluid. Subclinical hypocalcemic animals in their study also had deceased numbers of neutrophils and a reduction in PMN phagocytosis and oxidative burst, after incubation with pathogenic bacteria, that persisted for $42 \mathrm{~h}$ even after serum ionized $\mathrm{Ca}$ had returned to baseline concentrations. Finally, Martinez et al. (2012) reported that SCH cows had decreased percentages of PMN undergoing phagocytosis and oxidative burst. In their study, SCH animals had greater risk of developing fever, metritis, and puerperal metritis, reduced pregnancy rate, and a longer interval to pregnancy compared with normocalcemic cows. Increasing serum Ca by $0.25 \mathrm{mM}$ in their study reduced the relative risk of developing metritis by $22 \%$. Although total serum Ca was not affected after supplementation with oral $\mathrm{Ca}$ boluses in the current study, the increase in intracellular Ca may affect PMN function.

In the current study, oral Ca boluses appear to have had a mild effect on PMN function. The effect was more pronounced in primiparous animals given $50 \mathrm{~g}$ of oral $\mathrm{Ca}$. The oral $\mathrm{Ca}$ dose response data indicated that $50 \mathrm{~g}$ of $\mathrm{Ca}$ increased phagocytosis and oxidative burst intensity and numerically increased percentages of PMN undergoing phagocytosis and oxidative burst among primiparous animals. Twenty-five grams did not have a treatment effect and may not have been enough Ca to increase PMN function, which is consistent with the lack of an effect on intracellular PMN Ca. A numerical increase occurred for all measures of PMN function including phagocytosis, oxidative burst percent, phagocytosis intensity, and oxidative burst intensity in $50 \mathrm{~g}$ of oral $\mathrm{Ca} \times$ parity data; however, the increase was not statistically significant. In contrast, Miltenburg et al. (2018) did not observe any difference in PMN phagocytosis or oxidative burst at 3 DIM among periparturient 
animals administered Ca subcutaneously within $12 \mathrm{~h}$ of parturition and again $24 \mathrm{~h}$ later, compared with control cows given saline subcutaneously. The total amount of Ca delivered over the 2 injections was approximately $9.8 \mathrm{~g}$ from $\mathrm{Ca}$ gluconate and $\mathrm{Ca}$ glucoheptonate. Although Ca bolus supplementation appeared to increase $\mathrm{PMN}$ intracellular $\mathrm{Ca}$ in the days following calving in this study, PMN function depends on more than Ca for optimum function. A lack of significance of $\mathrm{Ca}$ bolus supplementation on PMN function in the $50-\mathrm{g}$ oral Ca bolus $\times$ parity data may be due to factors other than Ca. Polymorphonuclear leukocyte function is suppressed as a result of several stressors and physiological changes associated with the period surrounding parturition (Burton et al., 2005). Kehrli and Goff (1989) reported that periparturient cows injected intramuscularly with parathyroid hormone maintained greater plasma total calcium concentrations in early lacation; however, this was not associated with any restoration of the immune cell dysfunction that occurred around parturition. Those authors concluded that the immune cell dysfunction was likely not attributable to a single entity. The present data also indicate that $\mathrm{Ca}$ is likely not the only factor leading to suppressed PMN function. This may also partially explain why the $E$. coli-stimulated intracellular PMN Ca was not much different than under basal conditions. In summary, PMN function in the time surrounding calving may be suppressed due to several factors associated with the periparturient period. Supplementation with $50 \mathrm{~g}$ of oral Ca may help but likely is not sufficient to fully restore neutrophil function.

\section{CONCLUSIONS}

Oral Ca supplementation with $50 \mathrm{~g}$ of $\mathrm{Ca}$ as a blend of calcium chloride, calcium sulfate, and calcium propionate increased intracellular $\mathrm{PMN} \mathrm{Ca}$ in both primiparous and multiparous animals. Further, supplementing $50 \mathrm{~g}$ of oral Ca increased PMN phagocytosis and oxidative burst among primiparous animals but not multiparous animals. The lower dose of oral Ca, $25 \mathrm{~g}$, did not influence intracellular PMN Ca or PMN function. Therefore, these data indicate that $50 \mathrm{~g}$ of oral $\mathrm{Ca}$ for $2 \mathrm{~d}$ can increase intracellular PMN Ca and can play a role in restoring some of the impaired PMN function around parturition, especially among primiparous animals. These data further suggest that $\mathrm{Ca}$ is not the only factor limiting PMN function in the periparturient period and that oral Ca boluses are only part of a larger management strategy to improve periparturient health. Finally, these data suggest that the lower dose of oral $\mathrm{Ca}, 25 \mathrm{~g}$, is not enough to increase intracellular PMN $\mathrm{Ca}$ and restore some of the impaired PMN function.

\section{ACKNOWLEDGMENTS}

The authors thank Descanso Dairy in Abernathy, Texas, for allowing us to use their animals to conduct this study. The authors also thank Paulo Menta, Courtney Hoff, Maria Luiza Celestino, and Leticia Fernandes (Texas Tech University, Lubbock, TX) for their help in data collection. M. A. Ballou has equity ownership in MB Nutritional Sciences (Lubbock, TX). M. A. Ballou was involved in the design of the experiment and data analyses, and edited the final version of the manuscript. None of the other authors have any conflict of interest.

\section{REFERENCES}

Afshar Farnia, S., A. Rasooli, M. Nouri, A. Shahryari, M. Khosravi Bakhtiary, and P. D. Constable. 2018. Effect of postparturient oral calcium administration on serum total calcium concentration in Holstein cows fed diets of different dietary cation-anion difference in late gestation. R. Vet. Sci. 117:118-124. https://doi.org/10 .1016/j.rvsc.2017.11.017.

Blanc, C. D., M. Van der List, S. S. Aly, H. A. Rossow, and N. Silvadel-Río. 2014. Blood calcium dynamics after prophylactic treatment of subclinical hypocalcemia with oral or intravenous calcium. J. Dairy Sci. 97:6901-6906. https://doi.org/10.3168/jds.2014-7927.

Bréchard, S., and E. J. Tschirhart. 2008. Regulation of superoxide production in neutrophils: Role of calcium influx. J. Leukoc. Biol. 84:1223-1237. https://doi.org/10.1189/jlb.0807553.

Bryant, R. E. 1969. The effect of divalent cation depletion on phagocytosis of Staphylococci. Yale J. Biol. Med. 41:303-310.

Burton, J. L., S. A. Madsen, L. Chang, P. S. D. Weber, K. R. Buckham, R. van Dorp, M. C. Hickey, and B. Earley. 2005. Gene expression signatures in neutrophils exposed to glucocorticoids: A new paradigm to help explain "neutrophil dysfunction" in parturient dairy cows. Vet. Immunol. Immunopathol. 105:197-219. https: //doi.org/10.1016/j.vetimm.2005.02.012.

Chapinal, N., M. Carson, T. F. Duffield, M. Capel, S. Godden, M. Overton, J. E. P. Santos, and S. J. LeBlanc. 2011. The association of serum metabolites with clinical disease during the transition period. J. Dairy Sci. 94:4897-4903. https://doi.org/10.3168/jds .2010-4075.

Chapinal, N., S. J. LeBlanc, M. E. Carson, K. E. Leslie, S. Godden, M. Capel, J. E. P. Santos, M. W. Overton, and T. E. Duffield. 2012. Herd-level association of serum metabolites in the transition period with disease, milk production, and early lactation reproductive performance. J. Dairy Sci. 95:5676-5682. https://doi.org/10 .3168/jds.2011-5132.

Ducusin, R. J. T., Y. Uzuka, E. Satoh, M. Otani, M. Nishimura, S. Tanabe, and T. Sarashina. 2003. Extracellular $\mathrm{Ca}^{2+}$ on phagocytosis and intracellular $\mathrm{Ca}^{2+}$ concentrations in polymorphonuclear leukocytes of postpartum dairy cows. Res. Vet. Sci. 75:27-32. https:// doi.org/10.1016/S0034-5288(03)00038-9.

Ferguson, J. D., D. T. Galligan, and N. Thomsen. 1994. Principal descriptors of body condition score in Holstein cows. J. Dairy Sci. 77:2695-2703

Gronski, M. A., J. Kinchen, I. J. Juncadella, N. C. Franc, and K. S. Ravichandran. 2009. An essential role for calcium flux in phagocytes for apoptic cell engulfment and the anti-inflammatory response. Cell Death Differ. 16:1323-1331. https://doi.org/10.1038/ cdd.2009.55.

Kehrli, M. E. Jr., and J. P. Goff. 1989. Periparturient hypocalcemia in cows: Effects on peripheral blood neutrophil and lymphocyte function. J. Dairy Sci. 72:1188-1196. https://doi.org/10.3168/jds .S0022-0302(89)79223-7.

Kehrli, M. E. Jr., B. J. Nonnecke, and J. A. Roth. 1989. Alterations in bovine neutrophil function during the periparturient period. Am. J. Vet. Res. 50:207-214. 
Kimura, K., T. A. Reinhardt, and J. P. Goff. 2006. Parturition and hypocalcemia blunts calcium signals in immune cells of dairy cattle. J. Dairy Sci. 89:2588-2595. https://doi.org/10.3168/jds.S0022 -0302(06)72335-9.

LeBlanc, S. J., K. D. Lissemore, D. F. Kelton, T. F. Duffield, and K. E. Leslie. 2006. Major advances in disease prevention in dairy cattle. J. Dairy Sci. 89:1267-1279. https://doi.org/10.3168/jds.S0022 -0302(06)72195-6.

Leno, B. M., E. M. Martens, M. J. B. Felippe, K. P. Zanzalari, J. C. Lawrence, and T. R. Overton. 2017. Short communication: Relationship between methods for measurement of serum electrolytes and the relationship between ionized and total calcium and neutrophil oxidative burst activity in early postpartum dairy cows. J. Dairy Sci. 100:9285-9293. https://doi.org/10.3168/jds.2017-12971.

Leno, B. M., R. C. Neves, I. M. Louge, M. D. Curler, M. J. Thomas, T. R. Overton, and J. A. A. McArt. 2018. Differential effects of a single does of oral calcium based on postpartum plasma calcium concentration in Holstein cows. J. Dairy Sci. 101:3285-3302. https: //doi.org/10.3168/jds.2017-13164.

Littledike, E. T., and T. Goff. 1987. Interactions of calcium, phosphorous, magnesium, and vitamin $\mathrm{D}$ that influene their status in domestic meat animals. J. Anim. Sci. 65:1727-1743. https://doi .org $/ 10.2527 /$ jas1987.6561727x.

Makimura, S., and N. Suzuki. 1982. Quantitative determination of bovine serum haptoglobin and its elevation in some inflammatory diseases. Nippon Juigaku Zasshi 44:15-21.

Martinez, N., C. A. Risco, F. S. Lima, R. S. Bisinotto, L. F. Greco, E. S. Ribeiro, F. Maunsell, K. Galvão, and J. E. P. Santos. 2012. Evaluation of peripartal calcium status, energetic profile, and neutrophil function in dairy cows at low or high risk of developing uterine disease. J. Dairy Sci. 95:7158-7172. https://doi.org/10 $.3168 /$ jds.2012-5812.

Martinez, N., L. D. Sinedino, R. S. Bisinotto, R. Daetz, C. Lopera, C. A. Risco, K. N. Galvao, W. W. Thatcher, and J. E. Santos. 2016. Effects of oral calcium supplementation on mineral and acidbase status, energy metabolites, and health of postpartum dairy cows. J. Dairy Sci. 99:8397-8416. https://doi.org/10.3168/jds.2015 $-10527$.

Martinez, N., L. D. Sinedino, R. S. Bisinotto, E. S. Ribeiro, G. C. Gomes, F. S. Lima, L. F. Greco, C. A. Risco, K. N. Galvao, D. Taylor-Rodriguez, J. P. Driver, W. W. Thatcher, and J. E. Santos. 2014. Effect of induced subclinical hypocalcemia on physiological responses and neutrophil function in dairy cows. J. Dairy Sci. 97:874-887. https://doi.org/10.3168/jds.2013-7408.

Melendez, P., G. A. Donovan, C. A. Risco, and J. P. Goff. 2004. Plasma mineral and energy metabolite concentrations in dairy cows fed an anionic prepartum diet that did or did not have retained fetal membranes after parturition. Am. J. Vet. Res. 65:1071-1076. https://doi.org/10.2460/ajvr.2004.65.1071.
Miltenburg, C. L., T. F. Duffield, D. Bienzle, E. L. Scholtz, and S. J. LeBlanc. 2018. Short communication: The effect of calcium supplementation at calving on neutrophil function. J. Dairy Sci. 101:9505-9509. https://doi.org/10.3168/jds.2018-14839.

O'Flaherty, J. T., H. J. Showell, and P. A. Ward. 1977. Influence of extracellular $\mathrm{Ca}^{2+}$ and $\mathrm{Mg}^{2+}$ on chemotactic factor-induced neutrophil aggregation. Inflammation 2:265-276. https://doi.org/10 $.1007 / \mathrm{BF} 00921006$.

Oetzel, G. R., and B. E. Miller. 2012. Effect of oral calcium bolus supplementation on early lactation health and milk yield in commercial dairy herds. J. Dairy Sci. 95:7051-7065. https://doi.org/ 10.3168/jds.2012-5510.

Pehrson, B., C. Svensson, and M. Jonsson. 1998. A comparative study of the effectiveness of calcium propionate and calcium chloride for the prevention of parturient paresis in dairy cows. J. Dairy Sci. 81:2011-2016. https://doi.org/10.3168/jds.S0022-0302(98)75775 -3 .

Reinhardt, T. A., J. D. Lippolis, B. J. McCluskey, J. P. Goff, and R. L. Horst. 2011. Prevalence of subclinical hypocalcemia in dairy herds. Vet. J. 188:122-124. https://doi.org/10.1016/j.tvjl.2010.03.025.

Schaff, U. Y., I. Yamayoshi, T. Tse, D. Griffin, L. Kibathi, and S. I. Simon. 2008. Calcium flux in neutrophils synchronizes B2 integrin adhesive and signaling events that guide inflammatory recruitment. Ann. Biomed. Eng. 36:632-646. https://doi.org/10.1007/ s10439-008-9453-8.

USDA NAHMS. 2014. Dairy Cattle Management Practices in the United States, 2014. United States Department of Agriculture, Report 1. https://www.aphis.usda.gov/animal_health/nahms/dairy/ downloads/dairy14/Dairy14_dr_PartI_1.pdf.

Valldecabres, A., J. A. A. Pires, and N. Silva-del-Rio. 2018. Effect of prophylactic oral calcium supplementation on postpartum mineral status and markers of energy balance. J. Dairy Sci. 101:4460-4472. https://doi.org/10.3168/jds.2017-12917.

Wilhelm, A. L., M. G. Maquivar, S. Bas, T. A. Brick, W. P. Weiss, H. Bothe, S. Velez, and G. M. Schuenenmann. 2017. Effect of serum calcium status at calving on survival, health, and performance of postpartum Holstein cows and calves under certified organic management. J. Dairy Sci. 100:3059-3067.

\section{ORCIDS}

T. A. Batchelder ๑ https://orcid.org/0000-0002-3936-8270

E. M. Davis (ㄴ) https://orcid.org/0000-0002-8643-2095

V. S. Machado ( https://orcid.org/0000-0003-1513-8216

R. C. Neves (ㄴ) https://orcid.org/0000-0002-6595-3879

M. A. Ballou @ https://orcid.org/0000-0002-9843-1196 